\title{
Clinical utility gene card for FRMD7-related infantile nystagmus
}

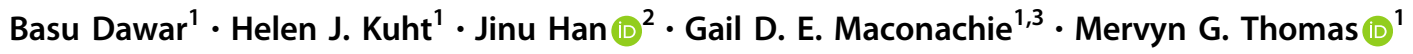

Received: 26 August 2020 / Revised: 29 December 2020 / Accepted: 24 January 2021 / Published online: 25 February 2021

(c) The Author(s), under exclusive licence to European Society of Human Genetics 2021

\section{Disease characteristics}

\subsection{Name of the disease (synonyms)}

FRMD7-related infantile nystagmus (FIN). Other relevant disease terminology:

Idiopathic infantile nystagmus (IIN) or X-linked IIN: FIN is considered a subtype.

Congenital idiopathic nystagmus or congenital motor nystagmus: Previous literature uses this term however it is no longer the preferred terminology. Since disease onset is within first six months of life, use of the term "infantile" is preferred over "congenital".

Infantile nystagmus syndrome (INS): This is an umbrella term used to group various forms of infantile nystagmus characterised by an accelerating slow phase velocity of nystagmus.

Therefore, can include disorders such as albinism. FIN is considered a subtype of INS.

\subsection{OMIM\# of the disease}

310700.

\subsection{Name of the analysed genes or DNA/ chromosome segments}

FERM domain-containing-protein 7 gene.

Mervyn G. Thomas

mt350@le.ac.uk

1 Ulverscroft Eye Unit, Department of Neuroscience, Psychology and Behaviour, University of Leicester, RKCSB,

PO Box 65, Leicester LE2 7LX, UK

2 Department of Ophthalmology, Gangnam Severance Hospital, Yonsei University College of Medicine, Seoul, Korea

3 Division of Ophthalmology and Orthoptics, Health Sciences School, University of Sheffield, Sheffield, UK

\subsection{OMIM\# of the gene(s)}

300628.

\subsection{Mutational spectrum}

Documented types of FRMD7 variants (https://databases. lovd.nl/shared/genes/frmd7) include splice, nonsense, missense, small indels, and large deletions [1-8].

\subsection{Analytical methods}

When the clinical phenotype is typical of FIN $[1,2,4]$, genetargeted testing or a multigene panel (for example nystagmus gene panel) is commonly used [3]. Gene-targeted testing involves techniques such as Sanger sequencing, and non-sequencing tests such as multiplex ligation-dependent probe amplification, comparative genomic hybridisation, and quantitative PCR to detect deletions/duplications. Multigene panels typically involve targeted next-generation sequencing (NGS) or exome/genome sequencing with virtual panels $[3,9]$. The latter techniques are useful in atypical cases or in infants and young children where limited phenotype data are available to narrow the clinical differentials. NGS can be used as a frontline diagnostic tool for infantile nystagmus [3].

Sanger sequencing involves sequencing 12 coding exons and flanking intronic sequences of the FRMD7 gene (NCBI reference sequence: NM_194277.3).

\subsection{Analytical validation}

Sanger sequencing would identify all coding and canonical splice variants. However, deep intronic variants and copy number variations (for example large deletions) would not be detected. NGS using a nystagmus gene panel can detect deep intronic variants and copy number variants [3]. The functional analysis combined with in-silico variant prediction is useful in validating novel variants. 


\subsection{Estimated frequency of the disease}

(Incidence at birth ("birth prevalence") or population prevalence. If known to be variable between ethnic groups, please report):

FIN is a subtype of INS. In the UK, INS has an estimated prevalence of 14.0 in 10,000 [10], while in Denmark the estimated prevalence of INS is 6.1 in 10,000 [11]. The reasons for the difference in prevalence are unclear, it could be because of differing study methodology or underlying population demographics. The idiopathic group which includes FIN has an estimated prevalence of 1.9 in 10,000 in the UK [10].

\subsection{Diagnostic setting}

\begin{tabular}{lll} 
& Yes. & No. \\
A. (Differential) diagnosis & $\bigotimes$ & $\square$ \\
B. Predictive Testing & $\square$ & $\square$ \\
C. Risk assessment in Relatives & $\bigotimes$ & $\square$ \\
D. Prenatal & $\bigotimes$ & $\square$ \\
\hline
\end{tabular}

Comment: Not applicable

\section{Test characteristics}

genotype or A: true positives C: false negative
disease

present absent B: false positives D: true negative test

$\begin{array}{ccll}\text { pos. A } & \text { B } & \begin{array}{l}\text { sensitivity: } \\ \text { specificity: }\end{array} & \mathrm{A} /(\mathrm{A}+\mathrm{C}) \\ & & \mathrm{D} /(\mathrm{D}+\mathrm{B}) \\ \text { neg. } \mathrm{C} & \mathrm{D} & \begin{array}{l}\text { pos. predict. value: } \\ \text { neg. predict. value: }\end{array} & \mathrm{D} /(\mathrm{C}+\mathrm{C}+\mathrm{D})\end{array}$

\subsection{Analytical sensitivity (proportion of positive tests if the genotype is present)}

If the genotype is present, Sanger sequencing would detect most variants $(<100 \%)$, however, deep intronic variants (for example c.285-118C > T) $[3,5]$ and copy number variants could potentially be missed [3, 8, 12]. Thus, NGS with coverage of known deep intronic regions together with a supplementary copy number diagnostic test would have higher analytical sensitivity than Sanger sequencing [3].

\subsection{Analytical specificity (proportion of negative tests if the genotype is not present)}

With Sanger sequencing, risks of false positives are rare therefore the estimated analytical specificity is nearly $100 \%$. NGS captures multiple genes associated with nystagmus therefore has a risk of misinterpretation of rare variants and hence false positives. However, previous work using a nystagmus gene panel has shown specificity above $99 \%$ [3]. A multi-disciplinary approach involving ophthalmologists together with clinical geneticists is helpful in reducing the risk of variant misinterpretation and accurately classifying novel variants in the context of the clinical findings.

\subsection{Clinical sensitivity (proportion of positive tests if the disease is present)}

Clinical sensitivity is dependent on the age of the patient and whether there is a family history $[1,4]$. Previous data suggest that sequence analysis in "idiopathic" familial cases (where two or more members are affected) identified a variant affecting function in $57-100 \%$ of cases [1, 2, 13-19]. While in simplex cases this varies between $0-29 \%[1,2,13,14,20]$. The lower rates of sensitivity in some studies could be due to missed variants within deep intronic regions [3] or cis-regulatory elements yet to be characterized. In addition, if a copy number variant analysis is not performed the sensitivity will be reduced [3].

\subsection{Clinical specificity (proportion of negative tests if the disease is not present)}

A study of 26 families with idiopathic X-linked congenital nystagmus and 42 sporadic cases identified 25 variants in FRMD7 in total. Male controls $(n=300)$ were also tested and no FRMD7 variants were identified, suggesting specificity close to $100 \%$ [1]. A more recent study using a NGS targeted panel for patients with infantile nystagmus had a specificity of $99.9 \%$ [3].

\subsection{Positive clinical predictive value (life time risk to develop the disease if the test is positive)}

With a hemizygous FRMD7 variant that affects function, the lifetime risk is $100 \%$ in males. In females with a heterozygous FRMD7 variant that affects function, reports on penetrance have varied. In larger studies penetrance has been estimated at $\sim 50 \%[1,21]$. To date, there have been two reports of females with homozygous FRMD7 variants $[18,22]$. Homozygous $F R M D 7$ variants known to affect function in females are associated with $100 \%$ risk of developing the disease. 


\subsection{Negative clinical predictive value (probability not to develop the disease if the test is negative)}

Assume an increased risk based on family history for a nonaffected person. Allelic and locus heterogeneity may need to be considered.

Index case in that family had been tested:

If a non-affected relative is negative for the diseasecausing variant identified in the index case, it is highly predictive of unaffected status and the negative clinical predictive value will be close to $100 \%$. There is no increased risk other than a small risk related to the prevalence in the general population. Typically, the phenotype is evident in the first six months of life. Therefore, in an older non-affected relative this is not applicable.

Index case in that family had not been tested:

If the index case has no evidence of nystagmus by six months of age, it is highly predictive of unaffected status and the negative clinical predictive value will be close to $100 \%$.

\section{Clinical utility}

\section{1 (Differential) diagnostics: The tested person is clinically affected (To be answered if in 1.9 "A" was marked)}

\subsubsection{Can a diagnosis be made other than through a genetic test?}

No. (continue with 3.1.4) $\quad \square$

Yes.

$$
\begin{aligned}
& \text { Clinically } \\
& \text { Imaging } \\
& \text { Endoscopy } \\
& \text { Biochemistry } \\
& \text { Electrophysiology } \\
& \text { Other (please describe): }
\end{aligned}
$$

One can suspect a diagnosis of FIN based on the typical clinical features, but confirmation requires genetic testing.

\subsubsection{Describe the burden of alternative diagnostic methods to the patient}

Not applicable.
3.1.3 How is the cost effectiveness of alternative diagnostic methods to be judged?

Not applicable.

3.1.4 Will disease management be influenced by the result of a genetic test?

No

Yes

No targeted therapies exist for FIN. However, there are therapies aimed at improving nystagmus and visual acuity.

Optical devices

FIN patients can present with reduced visual acuity. There is no clear evidence to support contact lenses over spectacles in these patients. Prisms can be beneficial for patients whose nystagmus is reduced on convergence.

\section{Pharmacology}

In infantile nystagmus, memantine and gabapentin have been shown to improve visual acuity, reduce nystagmus intensity, and improve foveation [23].

\section{Surgery}

Patients with FIN typically have null zone (gaze position where nystagmus intensity is lowest) in primary position thus less likely to adopt a head posture. However, when the null zone is not in the primary gaze position this leads to an abnormal head posture; occurring in $\sim 15 \%$ of cases [21]. Abnormal head posture can lead to neck pain and reduced vision, particularly if the patient is not looking through the centre of their glasses. Anderson-Kestenbaum surgery, which involves manipulating the extraocular muscles to shift the null point to primary gaze position, can correct abnormal head posture.

\section{Prognosis}

FIN is considered a stable disorder with better visual function compared to other causes of infantile nystagmus such as albinism, PAX6 variants affecting function and achromatopsia. However, to date there have been no natural history studies looking at the evolution of this disease and if it changes with age.

Regular follow-up is recommended to monitor changes in refractive error and to diagnose and manage any strabismus/amblyopia that may develop during childhood.

Consultation with a genetic counsellor or clinical geneticist can aid in deciding whether other family members should be tested for FRMD7 variants to determine carrier status and discuss family planning, DNA banking, and prenatal testing [4]. 
3.2 Predictive setting: the tested person is clinically unaffected but carries an increased risk based on family history

(To be answered if in 1.9 " $\mathrm{B}$ " was marked).

\subsubsection{Will the result of a genetic test influence lifestyle and} prevention?

If the test result is positive (please describe) Not applicable.

If the test result is negative (please describe) Not applicable.

3.2.2 Which options in view of lifestyle and prevention do a person at-risk have if no genetic test has been done (please describe)?

Not applicable.

\subsection{Genetic risk assessment in family members of a diseased person}

(To be answered if in 1.9 "C" was marked).

\subsubsection{Does the result of a genetic test resolve the genetic situation in that family?}

Yes. FIN is an X-linked disorder, with $100 \%$ penetrance in males and $\sim 50 \%$ penetrance in females [21]. Therefore, after molecular confirmation in the proband, segregation can be assessed and carrier testing in heterozygous females will help resolve the genetic situation in the family.

\subsubsection{Can a genetic test in the index patient save genetic or other tests in family members?}

Identification of a variant that affects function in the index case could potentially obviate the need for further investigations such as electrodiagnostic testing in other affected family members. In females, the penetrance is estimated at $50 \%$ therefore additional genetic testing in unaffected female family members to establish carrier status may prove useful.

\subsubsection{Does a positive genetic test result in the index patient} enable a predictive test in a family member?

FIN typically develops within six months of age therefore performing genetic testing on a family member below six months of age might have predictive value.

\subsection{Prenatal diagnosis}

(To be answered if in 1.9 "D" was marked).
Prenatal diagnosis is offered to patients with a FRMD7 variant that affects function to enable them to be fully informed. Female offspring of a male with FIN will be carriers, but $\sim 50 \%$ of female carriers will be affected. All male offspring of a male with FIN will be unaffected.

3.4.1 Does a positive genetic test result in the index patient enable a prenatal diagnosis?

Yes.

\section{If applicable, further consequences of testing}

Please assume that the result of a genetic test has no immediate medical consequences. Is there any evidence that a genetic test is nevertheless useful for the patient or his/her relatives? (Please describe).

Prompt genetic diagnosis of $F R M D 7$ variants provides opportunities for genetic counselling and testing of siblings with nystagmus. Testing of unaffected females may help with identifying carriers $(\sim 50 \%$ penetrance $)$ and facilitate genetic counselling.

Confirmation of a FRMD7 variant known to affect function reduces the need for a battery of investigations such as electrodiagnostic tests or brain imaging, thus decreasing the burden on patients and healthcare providers. Currently, no curative treatments are available.

Acknowledgements This work was supported by EuroGentest2 (Unit 2: "Genetic testing as part of health care"), a Coordination Action under FP7 (Grant Agreement Number 261469) and the European Society of Human Genetics. MGT is supported by the NIHR (CL-2017-11-003). BD is supported by the NIHR (ACF-2019-11003). MGT acknowledges the support from Fight for Sight, Medical Research Council, Ulverscroft Foundation and the Academy of Medical Sciences. JH is supported by the Research of Korea Centers for Disease Control and Prevention (\#2018-ER6902-00).

\section{Compliance with ethical standards}

Conflict of interest The authors declare no competing interests.

Publisher's note Springer Nature remains neutral with regard to jurisdictional claims in published maps and institutional affiliations.

\section{References}

1. Tarpey P, Thomas S, Sarvananthan N, Mallya U, Lisgo S, Talbot CJ, et al. Mutations in FRMD7, a newly identified member of the FERM family, cause X-linked idiopathic congenital nystagmus. Nat Genet. 2006;38:1242-4.

2. Thomas MG, Crosier M, Lindsay S, Kumar A, Thomas S, Araki M, et al. The clinical and molecular genetic features of 
idiopathic infantile periodic alternating nystagmus. Brain. 2011; 134:892-902.

3. Thomas MG, Maconachie G, Sheth V, McLean RJ, Gottlob I. Development and clinical utility of a novel diagnostic nystagmus gene panel using targeted next- generation sequencing. Eur J Hum Genet. 2017;25:725-34.

4. Thomas MG, Maconachie G, Hisaund M, Gottlob I. FRMD7Related Infantile Nystagmus. In: Adam MP, Ardinger HH, Pagon RA, et al. eds. GeneReviews ${ }^{\circledR}$. Seattle (WA): University of Washington, Seattle; 1993.

5. Thomas MG, Crosier M, Lindsay S, Kumar A, Araki M, Leroy BP, et al. Abnormal retinal development associated with FRMD7 mutations. Hum Mol Genet. 2014;23:4086-93. https://doi.org/10. 1093/hmg/ddu122.

6. Watkins RJ, Thomas MG, Talbot CJ, Gottlob I, Shackleton S. The role of FRMD7 in idiopathic infantile nystagmus. J Ophthalmol. 2012:460956. https://doi.org/10.1155/2012/460956.

7. Watkins RJ, Patil R, Goult BT, Thomas MG, Gottlob I, Shackleton S. A novel interaction between FRMD7 and CASK: evidence for a causal role in idiopathic infantile nystagmus. Hum Mol Genet. 2013;22:2105-18. https://doi.org/10. 1093/hmg/ddt060.

8. AlMoallem B, Bauwens M, Walraedt S, Delbeke P, De Zaeytijd J, Kestelyn P, et al. Novel FRMD7 mutations and genomic rearrangement expand the molecular pathogenesis of X-linked idiopathic infantile nystagmus. Invest Ophthalmol Vis Sci. 2015; 56:1701-10.

9. Rim JH, Lee ST, Gee HY, Lee BJ, Choi JR, Park HW, et al. Accuracy of next-generation sequencing for molecular diagnosis in patients with infantile nystagmus syndrome. JAMA Ophthalmol. 2017;135:1376-85.

10. Sarvananthan N, Surendran M, Roberts EO, Jain S, Thomas S, Shah N, et al. The prevalence of nystagmus: the Leicestershire nystagmus survey. Invest Ophthalmol Vis Sci. 2009;50:5201-6.

11. Hvid K, Nissen KR, Bayat A, Roos L, Grønskov K, Kessel L. Prevalence and causes of infantile nystagmus in a large populationbased Danish cohort. Acta Ophthalmol. 2020;98:506-13.

12. Fingert JH, Roos B, Eyestone ME, Pham JD, Mellot ML, Stone E. Novel intragenic FRMD7 deletion in a pedigree with congenital X-linked nystagmus. Ophthalmic Genet. 2010;31:77-80.
13. Schorderet DF, Tiab L, Gaillard MC, Lorenz B, Klainguti G, Kerrison JB, et al. Novel mutations in FRMD7 in X-linked congenital nystagmus mutation in brief \#963 Online. Hum Mutat. 2007;28:525.

14. Self JE, Shawkat F, Malpas CT, Thomas NS, Harris CM, Hodgkins PR, et al. Allelic variation of the FRMD7 gene in congenital idiopathic nystagmus. Arch Ophthalmol. 2007;125:1255-6.

15. Zhang B, Liu Z, Zhao G, Xie X, Yin X, Hu Z, et al. Novel mutations of the FRMD7 gene in X-linked congenital motor nystagmus. Mol Vis 2007a;13:1674-9.

16. Zhang Q, Xiao X, Li S, Guo X. FRMD7 mutations in Chinese families with $\mathrm{X}$-linked congenital motor nystagmus. Mol Vis. 2007b;13:1375-8.

17. He X, Gu F, Wang Y, Yan J, Zhang M, Huang S, et al. A novel mutation in FRMD7 causing X-linked idiopathic congenital nystagmus in a large family. Mol Vis. 2008;14:56-60.

18. Kaplan Y, Vargel I, Kansu T, Akin B, Rohmann E, Kamaci S, et al. Skewed $\mathrm{X}$ inactivation in an $\mathrm{X}$ linked nystagmus family resulted from a novel, p.R229G, missense mutation in the FRMD7 gene. Br J Ophthalmol. 2008;92:135-41.

19. Chen J, Wei Y, Tian L, Kang X. A novel frameshift mutation in FRMD7 causes X- linked infantile nystagmus in a Chinese family. BMC Med Genet. 2019;20:5 https://doi.org/10.1186/s12881-0180720-8.

20. Choi JH, Jung JH, Oh EH, Shin JH, Kim HS, Seo JH, et al. Genotype and phenotype spectrum of FRMD7-associated infantile nystagmus syndrome. Invest Ophthalmol Vis Sci. 2018;59:3181-8.

21. Thomas S, Proudlock FA, Sarvananthan N, Robert EO, Awan M, McLean R, et al. Phenotypical characteristics of idiopathic infantile nystagmus with and without mutations in FRMD7. Brain. 2008;131:1259-67. https://doi.org/10.1093/brain/awn046.

22. Radhakrishna U, Ratnamala U, Deutsch S, Bartoloni L, Kuracha MR, Singh R, et al. Novel homozygous, heterozygous and hemizygous FRMD7 gene mutations segregated in the same consanguineous family with congenital X-linked nystagmus. Eur J Hum Genet. 2012;20:1032-6. https://doi.org/10.1038/ejhg.2012.60.

23. McLean R, Proudlock F, Thomas S, Degg C, Gottlob I. Congenital nystagmus: randomized, controlled, double-masked trial of memantine/gabapentin. Ann Neurol. 2007;61:130-8. https://doi. org/10.1002/ana.21065. 